Musées, Patrimoine et Culture scientifiques et techniques

$153 \mid 2014$

mai-juin 2014

\title{
À propos du récolement de leurs collections, les muséums, musées de France
}

Sylvie Grange

\section{OpenEdition \\ Journals}

Édition électronique

URL : http://journals.openedition.org/ocim/1411

DOI : 10.4000/ocim. 1411

ISSN : 2108-646X

Éditeur

OCIM

Édition imprimée

Date de publication : 25 juin 2014

ISSN : 0994-1908

Référence électronique

Sylvie Grange, "À propos du récolement de leurs collections, les muséums, musées de France », La Lettre de I'OCIM [En ligne], 153 | 2014, mis en ligne le 25 juin 2014, consulté le 19 avril 2019. URL http://journals.openedition.org/ocim/1411; DOI : 10.4000/ocim.1411 


\section{À propos du récolement de leurs collections,}

\section{les muséums, musées de France}

Ce numéro de La Lettre de l'OCIM paraît à une date significative pour l'ensemble des musées reconnus sous l'appellation de "Musée de France », institués par la loi du 2 janvier 2002, transcrite depuis lors dans le livre IV du Code du Patrimoine. Il s'est écoulé dix ans depuis que les textes mettant en application la loi ont été pris (juin 2004). Cette décennie correspond au délai qui avait été choisi pour que soit clôt le premier récolement des collections auxquelles la loi avait conféré une protection juridique exceptionnelle. Précisément, souvenons-nous des circonstances de son vote : rejoindre les principes de la domanialité publique, en s'inscrivant en faux contre la tentative de collections «à double vitesse » qu'un projet de texte antérieur à celui finalement voté au Parlement avait un temps envisagé. La partie gagnée d’asseoir juridiquement l'inaliénabilité et l'imprescriptibilité de la totalité des collections avait une double contrepartie. En premier lieu, le corollaire de la reconnaissance de ce caractère exorbitant du droit commun requérait une collégialité effective des décisions majeures touchant aux collections, à l'occasion de leur acquisition et de leur conservation-restauration. Cette mise en partage sera organisée au plus près des acteurs, par le biais de commissions régionales ou inter-régionales, au sein des Directions Régionales des Affaires Culturelles (DRAC), avec une instance à Paris limitée aux fonds constitutifs ou aux procédures de recours. Deuxième volet, le champ d'application des nouvelles mesures de protection de ce patrimoine devait être parfaitement circonscrit. Il devait matérialiser juridiquement le dénombrement des fonds, en formalisant les inventaires, et assurer leur inscription dans le temps, par un récolement, dont la périodicité décennale signifiait qu'il devenait, de fait, une tâche permanente. Cela n'irait pas sans modifier les pratiques des professionnels concernés.

La circulaire fixant les conditions d'appréciation entre ce qui serait reconnu comme collection, donc devant être précisément inventorié et/ou récolé, et ce qui ne serait encore que matériel d'étude mit du temps à voir le jour. Il était judicieux de ne pas raviver des velléités de dispersion toujours latentes vis à vis de certaines catégories de collections, il était difficile de trancher entre modes différenciés de reconnaissance patrimoniale affectant un même type d'objet. Déterminer les critères de la patrimonialisation en dehors des schémas induits par la recherche d'ordre esthétique ou la prise en compte de la pièce unique s'avéra délicat. Les collections fondées sur les valeurs d'usage, la notion de série, et de ce fait même sur les corpus les plus étendus à traiter, ont bien dû se constituer une feuille de route, car le temps courrait. Or, le premier récolement allait être le plus dur à réaliser, souvent concomitant d'inventaires rétrospectifs.

Dans la grande famille des 1220 musées de France, une branche va développer une posture particulièrement pragmatique et efficace face au double défi évoqué à l'instant. Ce sont les muséums. Sans rien perdre des liens privilégiés entretenus par et avec le ministère de l'Éducation nationale, de l'Enseignement supérieur et de la Recherche (MESR) - qui fonda l'OCIM en 1985 pour être à leur service - les muséums ont investi les commissions pour y porter les questions qu’appelait, croyaient-ils, la spécificité de leurs fonds, 
posant en réalité des interrogations sur des types de protocoles, de mises en contexte, de formes de scientificité qui pouvaient interpeller l'ensemble des professionnels. Les muséums ont sans doute plus appris des autres musées que ceux-ci n'ont su le faire auprès d'eux.

Leur habilité ne s'est pas arrêtée là : ils ont su gagner une reconnaissance publique en investissant le débat citoyen par leurs collections, mais aussi par la mise en avant d'une posture de questionnement en fait d'écologie, de développement durable ou d'environnement. Cette plasticité, que chacun développe en fonction de son milieu, s'est accompagnée d'un renforcement des liens qu'ils ont souhaité avoir entre eux. La création il y a trois ans de la Conférence Permanente des Muséums de France (CPMF) concrétise cette belle dynamique. C'est un format de réseau souple, opératoire, fédéré par simple adhésion à une charte rédigée à cette intention. Cet organe représentatif n'est pas à l'unanimité de ses membres potentiels, ce qui constitue sans doute le meilleur indice de la liberté qui préside aux relations, des institutions les plus petites aux plus grandes.

Leétat des lieux du récolement en 2014 révélera-t-il un nouvelle fois cette capacité d'adaptation? Les professionnels des muséums ont la parole pour exposer leurs points de vue sur cette question, lisez-les avec intérêt et curiosité ! Parmi les musées de France qui obtiendront les plus faibles écarts à la marge dans le respect du délai initial du premier récolement, gageons que les muséums ne seront pas les moins bien placés!

Sylvie Grange

Conservateur en chef du patrimoine

Directrice de l'OCIM 